\title{
Improving the Accuracy of Hydrocarbon Reserves Estimation Based on an Integrated Approach
}

\author{
D.A. Zavyalov ${ }^{1}$ \\ zda@tpu.ru \\ ${ }^{1}$ Tomsk Polytechnic University, Tomsk, Russia
}

\begin{abstract}
The paper presents an integrated approach to computer modeling of hydrocarbon deposits, as well as the results of its application in oil volume calculation. Such approach involves all available information, as well as visual analytics, and allows to get a more accurate and reliable distribution of parameters in the volume of the three-dimensional computer model of hydrocarbon deposit due to its adjustment based on actual (historical) information about the operation of the oil field. The adjusted in this way model allows to obtain a more accurate predictive solution for the development and to improve the management efficiency of hydrocarbon deposits.
\end{abstract}

Keywords: oil and gas field, oil field managing, oil volume calculation, integrated approach, visual analytics.

\section{Introduction}

The hydrocarbon field is a large socio-economic system (SES) that has a complex hierarchical structure and is closely interconnected with other SES (administratively, infrastructurally, economically), and sometimes determines their progress. The hydrocarbon field includes both underground oil deposits and ground-based infrastructure (pipelines, power plants, residential and working premises, roads, etc.), as well as drilled wells (oil-production, injection, water-production, and others). Usually three organizational systems participate in managing a field at different stages: the state, a subsoil user company, and a project institute, which include specialists of different profiles, whose interaction is often inconsistent.

Considering the volume of capital investments (the cost of drilling and developing wells, conducting research and field works) and the operating costs of developing the fields, as well as the degree of uncertainty in carrying out the works, the planning task becomes critical in managing the field as a socioeconomic system. This problem is solved with the development designing process, the result of which is a long-term strategy for the functioning of the field.

The basis of any field development project is detailed threedimensional computer model, the accuracy and reliability of which determine the feasibility of the development strategy, and therefore the management efficiency of the SES "hydrocarbon field" [1].

\section{Three-dimensional computer models of hydrocarbon fields}

The field model is a three-dimensional digital interpretation of the real formation according to a number of parameters (porosity, permeability, oil saturation, etc.), and the modeling process itself is the restoration of those parameters from several observation points (studies in drilled wells). Obviously, in the early stages of deposits lifecycle, the reliability of geological models is lower due to the smaller number of such observation points. However, the reliability of the models is determined not only by the density of the grid of observations or the quality of research, but also by the complexity and heterogeneity of the geological structure of the field. To increase the reliability of field models, an integrated approach to modeling is required, which means the involving of all available information, as well as visualization tools and visual analytics.

\section{An integrated model of hydrocarbon field}

In this paper, the effectiveness of the use of an integrated field model by the effect on the reliability (in terms of accuracy of estimating oil reserves) of the geological model and reserves estimation is assessed.
To assess the reliability of oil reserves estimation on the basis of the integrated model, one of the fields of Tomsk Region the designing history of which includes more than one reserves calculation project was selected. There are geological models and protocols about approved oil reserves on their basis, as well as data on drilled production wells and retrospective information (historical data) on their operation regimes (table 1).

Table 1. Projects on development of hydrocarbon fields

\begin{tabular}{|c|c|c|c|}
\hline & $\begin{array}{c}\text { Hydrocarbon } \\
\text { reserves } \\
\text { estimation }\end{array}$ & $\begin{array}{c}\text { Development } \\
\text { project }\end{array}$ & $\begin{array}{c}\text { Model } \\
\text { adjustment }\end{array}$ \\
\hline 2006 & $\checkmark$ & & \\
\hline 2007 & & $\checkmark$ & \\
\hline 2008 & $\checkmark$ & & $\checkmark$ \\
\hline 2009 & & $\checkmark$ & \\
\hline 2010 & & & \\
\hline 2011 & $\checkmark$ & & \\
\hline 2012 & & $\checkmark$ & \\
\hline 2013 & & & \\
\hline 2014 & & $\checkmark$ & \\
\hline 2015 & & & \\
\hline 2016 & & $\checkmark$ & \\
\hline
\end{tabular}

The first hydrocarbon reserves estimation at the field was carried out in 2006, the subsequent ones were in 2008 and 2011. Industrial development of the field has been conducted from 2008 to the present (data are available till 2016).

As an illustration of changes in ideas about the geological structure of the field, fig. 1 shows the structural maps of the top of the reservoir in different years of calculating reserves, which were approved at the state level. Fig. 2 presents the history of the designing of this field based on available project and historical data.

The volume of oil reserves approved in 2006 at the field was 5,825 thousand tons. This calculation was carried out on the eastern part of the reservoir, in which an inflow of oil from a drilled well was obtained.

In 2007, on the basis of the first oil reserves calculation, the first project document for the field was developed, according to which its commercial operation began in 2008. The oil inflows got in 3 drilled wells gave reason to carry out a new calculation of oil reserves in 2008 and to put the remaining oil deposits on the balance of the subsoil user (the volume of reserves increased to 17,744 thousand tons) - the reservoir area has increased according to the modelling results. 


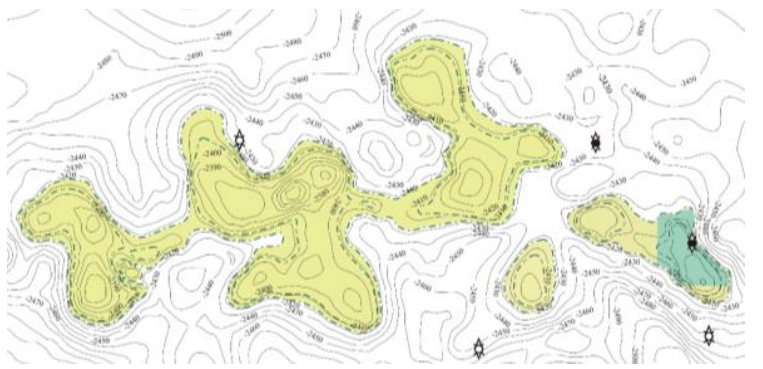

a)

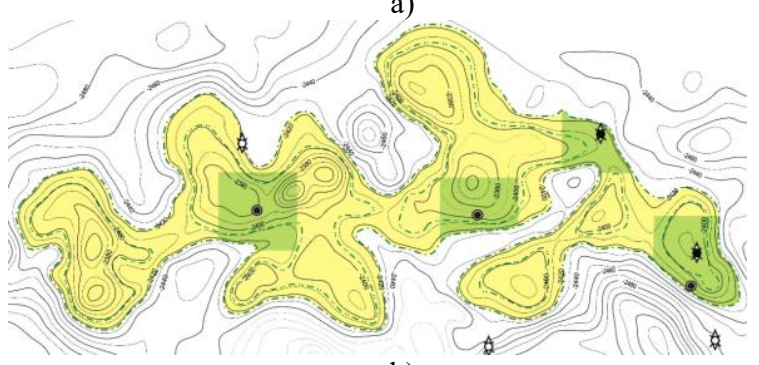

b)

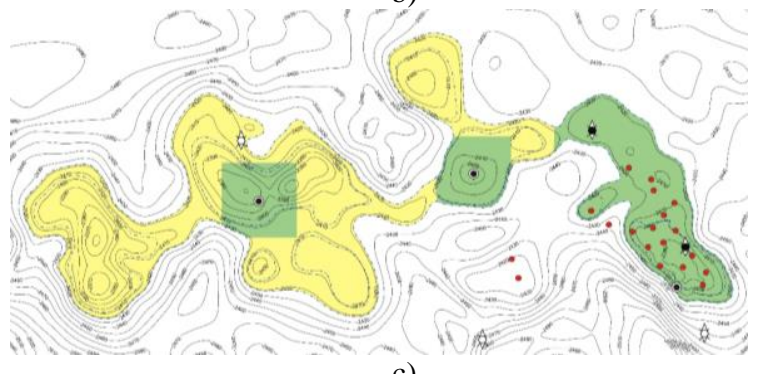

Fig. 1. Change of ideas about the geological structure of the field in time: a) 2006, b) 2008, c) 2011
Based on the second reserves calculation, in 2009 a new project document was developed for the operation of the field, which involved intensive drilling of the reservoir - 19 new wells were drilled, some of which did not confirm the oil content of part of the reservoir. Thus in 2011, the third calculation of reserves was carried out, which reduced the area of the deposit and the reserves - their volume decreased to 15,973 thousand tons of oil.

Fig. 2 shows a comparison of designed and historical indicators of annual oil production in the field. Throughout the entire period of the field's operation, the actual volumes of oil production lag behind the designed ones.

Each project document for the development of a field implies an analysis of its development history. Among the reasons for the failure to achieve the approved project indicators, in addition to high expectations and the erroneous idea of the geological structure of the field, experts in the reports indicate a higher actual water cut than in the project, which along with relative phase permeabilities is determined by the property of initial water saturation in the field model. Thus, in this case, we can speak of an overestimated value of the initial oil saturation in the field model.

For putting on the state balance, oil reserves are estimated as the sum of the oil volume of all cells of the effective oilsaturated part of the 3D-geological model (fig. 3). The volumetric method is the following:

$$
V o=\rho o * B o * \sum_{i=1}^{n}\left(V b_{i} * \text { Poro }_{i} * S o_{i}\right),
$$

where $V o$ is the volume of oil reserves; $i, n$ - respectively, the index and the number of cells in the model; $V b_{i}-$ the rock volume, $\mathrm{Pror}_{i}$ - the porosity coefficient, $\mathrm{So}_{i}$ - the oil saturation coefficient of the $i$-th cell of the model; $\rho$ - the oil density; $B o$ - the volumetric coefficient of oil $[2,3]$.

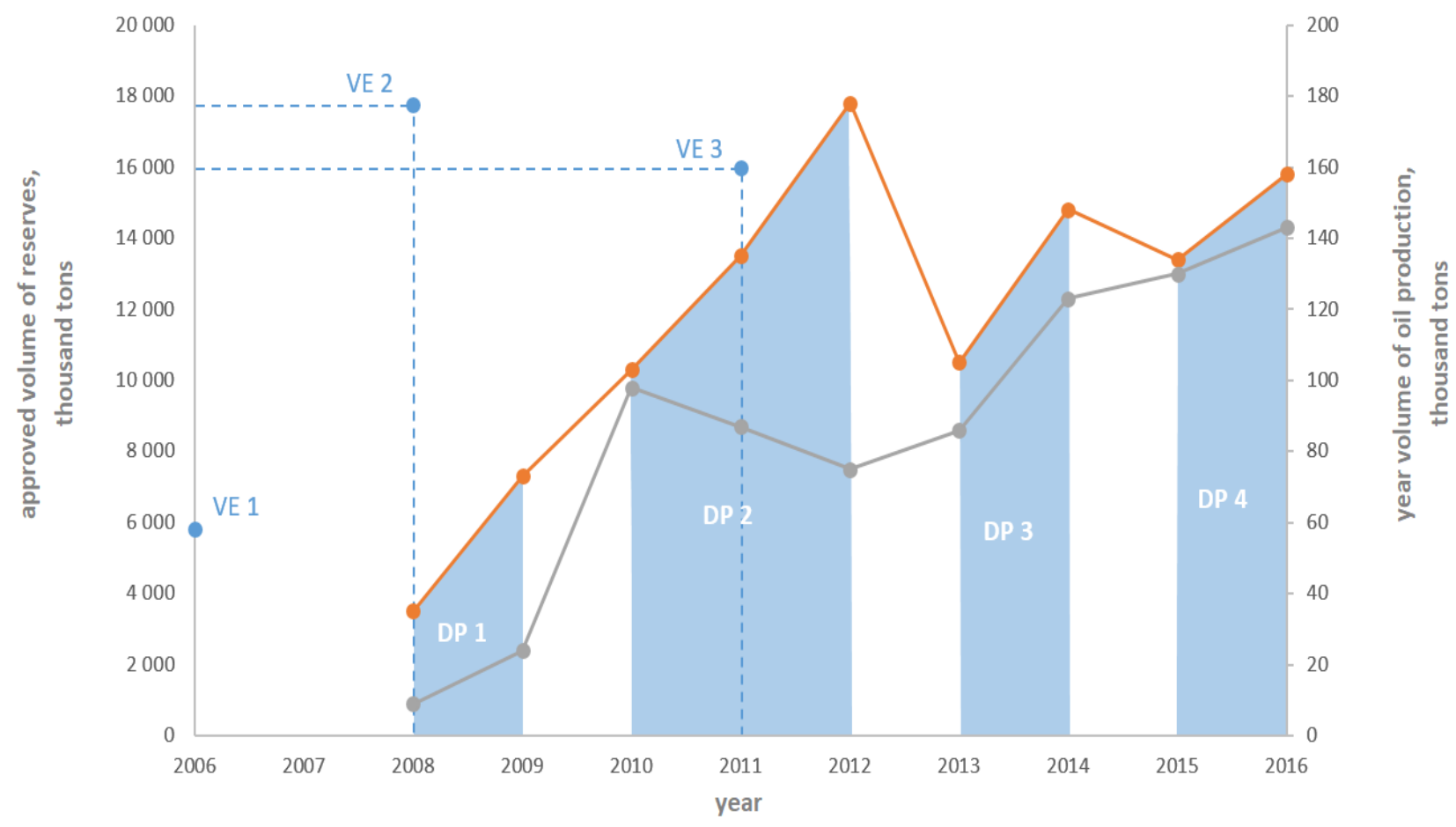

project oil production, thousand tons

historical oil production, thousand tons

Fig. 2. The history of the designing and production of oil in the field (VE - reserves volume estimation, DP - development project) 


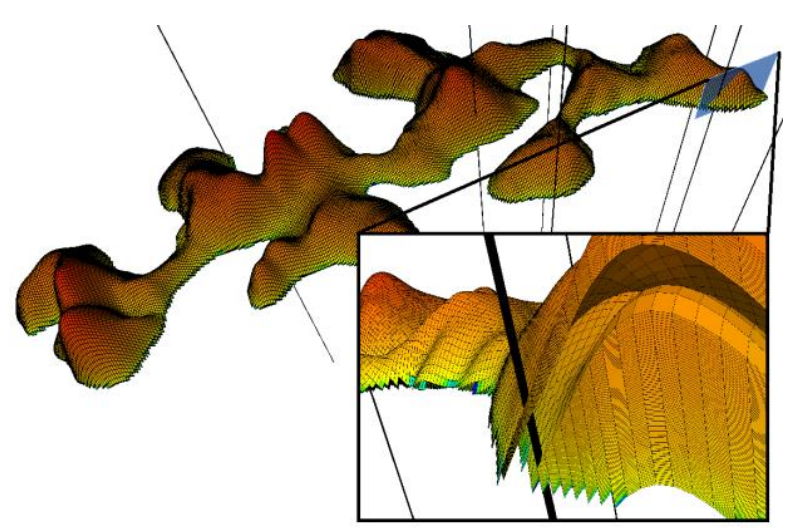

Fig. 3. 3D geological model of the field

Moreover, in a two-phase system (oil-water), the sum of saturations is equal to one, therefore, $S o$ in each cell of the model is calculated by the formula:

$$
S o=1-\left(\frac{3,183 *(\rho w-\rho o) * g * h}{A * \gamma * \cos (\theta)} * \sqrt{\frac{\text { Perm }}{\text { Poro }}}\right)^{-\frac{1}{B}},
$$

where $\rho w$ is the density of water, $\rho o-$ the density of oil, $g-$ the acceleration of gravity, $h$ - the height relative to the level of free water, $\gamma$ - the surface tension between oil and water, $\theta$ - the wettability angle, $A$ and $B$ are the coefficients of the power dependence of the Leverett J-function, which has the form:

$$
J(S w)=A * S w^{-B},
$$

where coefficients $A$ and $B$ are calculated on the basis of the results of laboratory core tests.

In geological modeling, the calculation of permeability in models is based on the results of geophysical studies in wells as a function of porosity. Darcy's law allows to solve the inverse problem of calculating the permeability value in the well area:

$$
K=q o * \frac{18.41 * \mu o * B o *\left(\ln \left(\frac{r e}{r w}\right)-0.75+S\right)}{h *(\bar{P} r-P w f)},
$$

where $q o$ is the oil production rate $\left(\mathrm{m}^{3} /\right.$ day), $K$ - the permeability (mD), $h$ - the effective reservoir thickness (m), Pr - the average reservoir pressure (atm), $P w f$ - the bottomhole pressure of the well (atm), $\mu o$ - the oil viscosity in reservoir conditions $(\mathrm{cP}), B o$ - oil volumetric coefficient $\left(\mathrm{m}^{3} / \mathrm{m}^{3}\right)$, re - drainage radius $(\mathrm{m}), r w$ - well radius (m), $S$ - skin factor.

In the designing of hydrocarbon field development, thematic mapping is widely used for operational monitoring of development, visual analysis of the history and development status, prediction of reservoir behavior and so on. In addition, such tools as time series analysis, slices of multidimensional data, sections of data cubes, geological and statistical sections and others are widely used for visual analytics $[4,5,6,7,8]$.

At the first step, to analyze the correspondence of the parameters of the field model to the real reservoir, maps of the distribution of the actual and model oil production were constructed, which made it possible to conclude that the geological model of the field was unreliable and there is the need for its correction. Based on a comparison of production maps, areas of the model that require adjustment of parameters were identified (fig. 4).

To correct permeability in the 2008 project model time series characterizing the dynamics of actual production of wells were analyzed, after that, based on (4) new values of permeability in wells were calculated. Interpolation of new values of permeability in the volume of the reservoir model allows to adjust the initial oil saturation according to (3), (2) and further recalculating of the initial oil reserves by formula (1).

The average value of reservoir permeability decreased by $12.1 \%$ (from $6.79 \mathrm{mD}$ to $5.97 \mathrm{mD}$ ), oil saturation decreased by $1.4 \%$ (from 0.579 u.f. to 0.571 u.f.), which led to a reduction in the recalculated oil reserves by $0.9 \%$ compared with the standard approach.

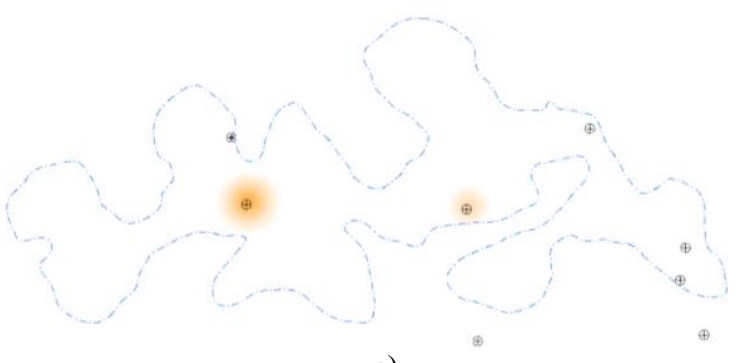

a)

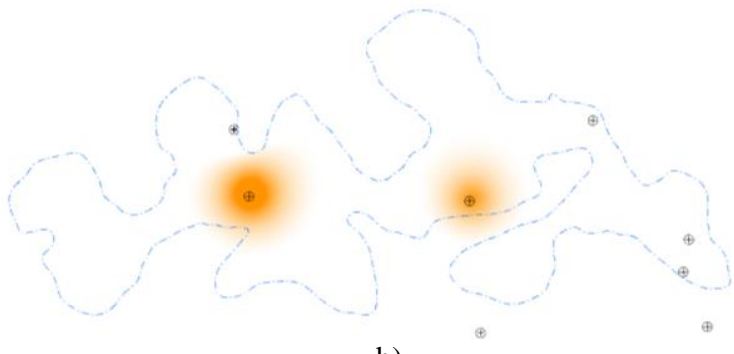

b)

Fig. 4. Oil production in wells: a) history, b) model

An integrated approach to geological modeling made it possible to obtain a more correct distribution of permeability (fig. 5), initial oil saturation (fig. 6) and initial oil reserves over the area and volume of the oilfield model, which makes it possible to obtain a more correct forecast decision and make more adequate field development strategy. The recalculated parameters turned out to be closer in value to the parameters obtained in the 2011 project, when $12 \%$ of oil reserves were written off.

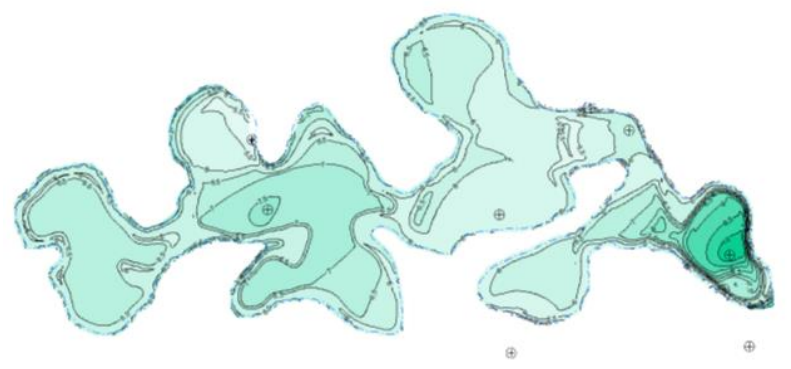

a)

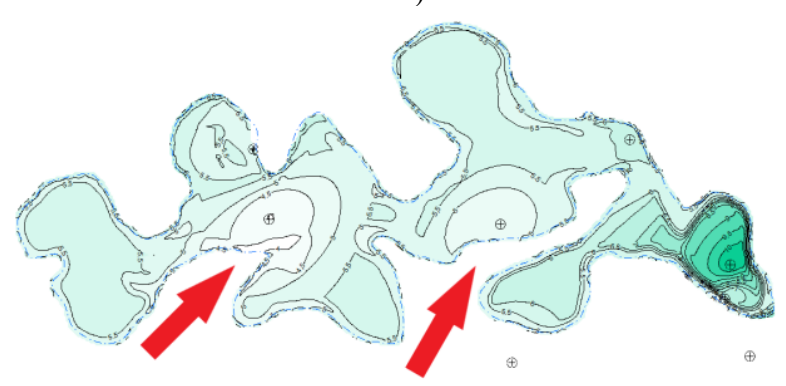

b)

Fig. 5. Average maps of permeability: a) approved model, b) adjusted

The use of such an integrated approach to modeling a number of fields has let to increase the accuracy of estimating hydrocarbon reserves by 0.7 to $3.2 \%$.

\section{Conclusion}

The paper presents an integrated approach to estimating the volume of hydrocarbon reserves, which allows to increase the accuracy of such an assessment and the reliability of the geological model of the field. The model adjusted in this way allows to obtain a more accurate predictive solution for the 


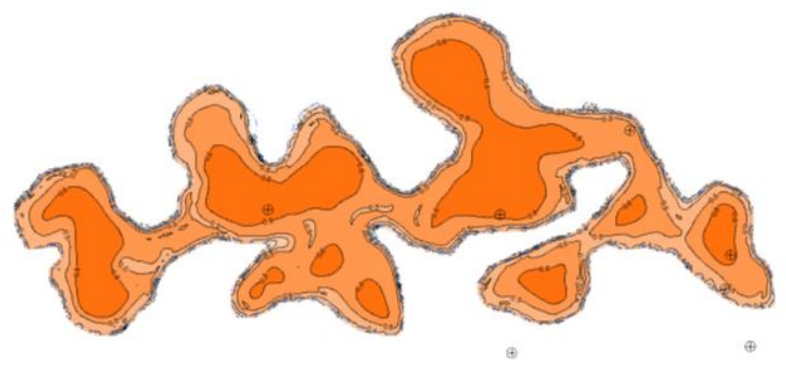

a)

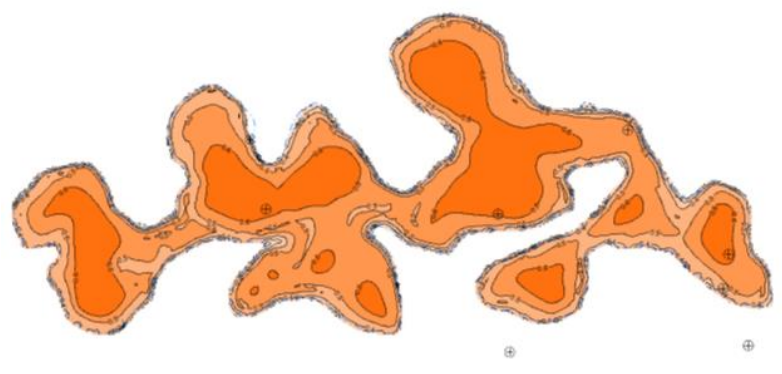

b)

Fig. 6. Average maps of oil saturation: a) approved model, b) adjusted model

\section{Acknowledgements}

This work has been supported by the Ministry of Education and Science of the Russian Federation with the Grant No. 2.1642.2017/4.6.

\section{References}

[1] Novikov D.A. Organizational Systems Management Theory. 3rd ed. - Moscow: Publishing house of physical and mathematical literature, 2012. - 604 p.

[2] Determining of design parameters for calculating reserves in oil fields based on the results of hydrodynamic studies of wells / Zakharova A.A. [and others] // Bulletin of Tomsk Polytechnic University [Bulletin of TPU]. - 2012. - V. 320, № 1: Earth sciences. - [P. 142-146]

[3] Zakrevsky K.E. Workshop on geological 3D modeling. Building a test model in Petrel $2009 / 2010 .-110$ p.

[4] Guidelines for the preparation of technical projects for the development of hydrocarbon fields // Ministry of Natural Resources of Russia. 18.05.2016

[5] Guidelines for the application of the classification of reserves and resources of oil and gas // Ministry of Natural Resources of Russia. 01.02.2016

[6] Ding, G., Xue, Y., Cao, R., Zhang, X. Fine 3-D geology modeling-based study of remaining oil distribution in Linpan oilfield // (2019) Springer Series in Geomechanics and Geoengineering, (216039), pp. 201-211.

[7] Yang, Y., Zhang, M., Bie, A., Cui, Z., Xia, Z. An integrated approach to uncertainty assessment for coalbed methane model // (2019) Springer Series in Geomechanics and Geoengineering, (216039), pp. 1560-1567.

[8] Pakyuz-Charrier, E., Giraud, J., Ogarko, V., Lindsay, M., Jessell, M. Drillhole uncertainty propagation for threedimensional geological modeling using Monte Carlo // (2018) Tectonophysics, 747-748, pp. 16-39. 